\title{
Headache, Facial Palsy, and Diplopia: An Unusual Presentation of Ruptured Distal Anterior Cerebral Artery Aneurysm
}

Sir, Intracerebral aneurysms may present with cranial nerve paresis in more than $20 \%$ cases. Nerve fibers may be compressed mechanically by the aneurysm sac or by the bleed from the ruptured aneurysm. ${ }^{[1]}$ However, the involvement of cranial nerves far away from the ruptured aneurysm is unusual. Here, we are discussing a case with unilateral sixth and seventh nerve palsy following ruptured distal anterior cerebral artery aneurysm who clinically improved after surgery.

A 30-year-old lady presented with a history of sudden onset headache and right side facial weakness. Initially, she was treated by a local physician with the diagnosis of stroke. There was no other comorbid illness. The day after the event, she had developed diplopia on looking toward the right side. Initial computed tomography (CT) scan showed intraventricular hemorrhage, anterior interhemispheric bleed with perimesencephalic hemorrhage [Figure 1a and b]. In suspicion of some vascular pathology, she was referred to our center. At presentation, she was conscious, alert without any focal motor power deficit. However, she had right sixth nerve and lower motor neuron type seventh nerve palsy (House and Brackmann grade IV) [Figure 1d]. On CT angiography, there was a saccular aneurysm at the junction of pericallosal and callosomarginal artery on the left side [Figure 1c]. She underwent bifrontal craniotomy with clipping of the aneurysm. The perioperative period was uneventful. The right seventh nerve palsy improved completely at 3-month follow-up with partial recovery of the sixth nerve [Figure 1e].

Cranial nerve involvement in cases of subarachnoid hemorrhage is commonly due to the mechanical pressure by the aneurysm. Unilateral oculomotor nerve palsy due to mechanical compression by posterior communicating-internal carotid artery aneurysm has been described in literature. ${ }^{[2]}$ The oculomotor nerve palsy has variable outcome with clipping and coiling and at times, the recovery may not be complete. ${ }^{[2,3]}$ Lower motor neuron 


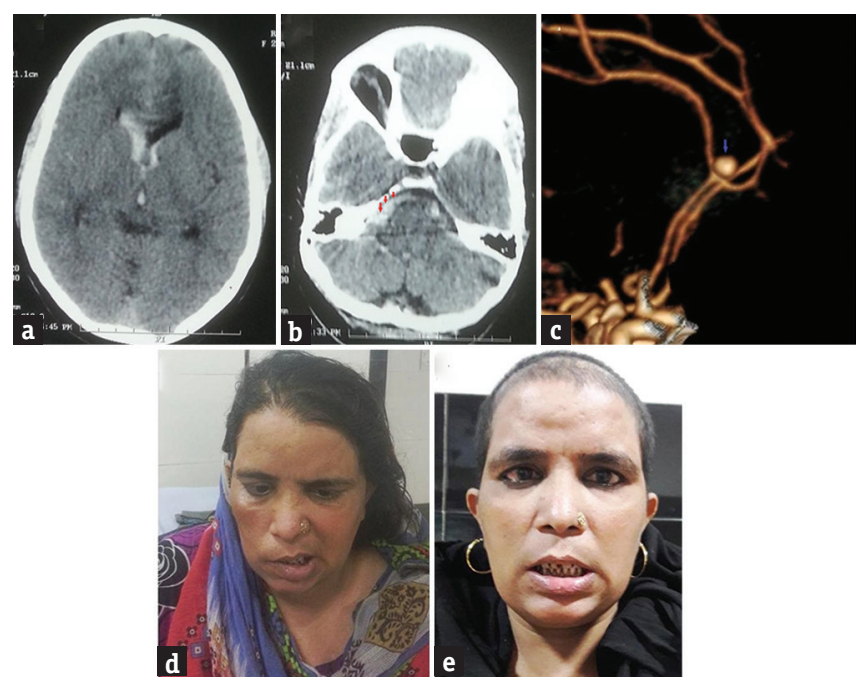

Figure 1: ( $a$ and b) Noncontrast computed tomography scan showing anterior interhemispheric bleed, intraventricular hemorrhage. Note the blood in the right cisternal space (red arrows). (c) Computed tomography angio showing the saccular aneurysm (blue arrow) at the junction of pericallosal and callosomarginal artery. (d) Preoperative patient image showing right-sided facial palsy. (e) Postoperative patient image showing the improvement of right-sided facial palsy

type facial nerve involvement found with anterior inferior cerebellar artery and vertebral artery-posterior inferior cerebellar artery aneurysm. Cases of nonaneurismal perimesencephalic cistern hematoma presenting with third nerve palsy have also been reported. ${ }^{[4]}$

Sudden onset facial palsy with headache in this case was initially considered as stroke. However, the persistence of headache and evolution of newer symptom (diplopia) mandate further evaluation. Blood in the right basal cistern space has caused direct compression over the right sixth and seventh nerve fibers. The additional mechanism of vasospasm of the arterial supply to the nerve nuclei may perhaps explain the same. ${ }^{[4]}$ In this case, both facial palsy and diplopia improved with time. However, direct compression of the nerve fibers by the aneurysmal sac has varied outcome as seen with third nerve palsy in cases of posterior communicating-internal carotid artery aneurysms. The degree of initial nerve palsy, the size of aneurysm, time, and type of intervention may influence the outcome. ${ }^{[3]}$ The present case supports that cranial nerve palsy may occur purely due to cisternal hemorrhage away from the ruptured aneurysm. The cisternal blood usually get resolves with time so also the vasospasm involving the arterial supply to the brainstem. This possibly explains the benign nature of this cranial nerve paresis in such cases.

\section{Declaration of patient consent}

The authors certify that they have obtained all appropriate patient consent forms. In the form the patient(s) has/have given his/her/their consent for his/her/their images and other clinical information to be reported in the journal. The patients understand that their names and initials will not be published and due efforts will be made to conceal their identity, but anonymity cannot be guaranteed.

\section{Financial support and sponsorship}

Nil.

\section{Conflicts of interest}

There are no conflicts of interest.

\author{
Sushant Sahoo, Chhitij Srivastava \\ Department of Neurosurgery, KGMU, Lucknow, \\ Uttar Pradesh, India \\ Address for correspondence: Dr. Sushant Sahoo, \\ Department of Neurosurgery, KGMU, Lucknow, \\ Uttar Pradesh, India. \\ E-mail:drsushantsahoo@gmail.com
}

\section{REFERENCES}

1. Kurokawa R, Saito R, Nakamura Y, Kagami H, Ichikizaki K. Ruptured vertebral artery-posterior inferior cerebellar artery aneurysm associated with facial nerve paresis successfully treated with interlocking detachable coils - Case report. Neurol Med Chir (Tokyo) 1999;39:863-6.

2. Chalouhi N, Theofanis T, Jabbour P, Dumont AS, Gonzalez LF, Starke RM, et al. Endovascular treatment of posterior communicating artery aneurysms with oculomotor nerve palsy: Clinical outcomes and predictors of nerve recovery. AJNR Am J Neuroradiol 2013;34:828-32.

3. Gaberel T, Borha A, di Palma C, Emery E. Clipping versus coiling in the management of posterior communicating artery aneurysms with third nerve palsy: A systematic review and meta-analysis. World Neurosurg 2016;87:498-506.e4.

4. Sadamasa N, Sano N, Takeda N, Yoshida K, Narumi O, Chin $\mathrm{M}$, et al. Perimesencephalic nonaneurysmal subarachnoid hemorrhage with unilateral third cranial nerve palsy: Two case reports. Neurol Med Chir (Tokyo) 2012;52:918-20.

This is an open access article distributed under the terms of the Creative Common Attribution-NonCommercial-ShareAlike 3.0 License, which allows others to remix, tweak, and build upon the work non-commercially, as long as the author is credited and the new creations are licensed under the identical terms.

\begin{tabular}{|l|l|}
\hline \multicolumn{2}{|c|}{ Access this article online } \\
\hline Quick Response Code: & Website: \\
\hline & www.ruralneuropractice.com \\
& \\
\hline
\end{tabular}

How to cite this article: Sahoo S, Srivastava C. Headache, facial palsy and diplopia: An unusual presentation of ruptured distal anterior cerebral artery aneurysm. J Neurosci Rural Pract 2017;8:487-8.

C 2017 Journal of Neurosciences in Rural Practice | Published by Wolters Kluwer - Medknow 